\title{
La guerrilla y la radio. El papel de Radio España Independiente en el movimiento guerrillero español (1941-1952)
}

\author{
Antonio Ortiz Mateos \\ Licenciado en Historia por la UNED
}

The guerrilla and the radio. The role of Independent Spain Radio in Spanish guerrilla movement (1941-1952)

\begin{abstract}
RESUMEN
Creada en 1941 para coordinar la acción de los comunistas españoles en los países invadidos por los nazis, caso de Francia, o bajo el franquismo, Radio España Independiente (REI) jugó un papel destacado tanto en la orientación política de los núcleos de militantes existentes como en la formación y desarrollo del movimiento guerrillero español en estos dos países. Todo ello inicialmente en el marco de una estrategia de defensa de la

URSS, «patria del socialismo», tras su invasión por los ejércitos alemanes.

ABSTRACT

Established in 1941 to coordinate the action of the Spanish Communists in the countries invaded by the Nazis, as France, or under Franco, Independent Spain Radio (REI) played an important role both in the political orientation of existing nuclei of militants and in the training and development of the Spanish guerrilla movement in these two countries. All this at the beginning within the framework of a strategy to defend the USSR, "homeland of socialism,» after its invasion by German armies.
\end{abstract}

PALABRAS CLAVE

KEY WORDS

Radio, Guerrilla, Comunismo, REI.

Radio, Guerrilla, Communism, REI.

En mayo de 2000 tuve ocasión de participar en la exposición «75 años de la radio en España. Homenaje a Radio España Independiente » 1 , lo que me permitió conocer a Ramón Mendezona, su último director. Salvo algunas referencias de Dolores Ibárruri y Teresa Pamiés, nada más se incluyó en ella sobre sus primeros años de vida. Las memorias de Luis Galán² o del propio Mendezona poco

\footnotetext{
1 Catálogo de la exposición: «75 aniversario de la radio en España. Homenaje a: Radio España Independiente». Madrid, Fundación Domingo Malagón, mayo 2000.

2 Luis Galán Jiménez ingresó en las Juventudes Comunistas en 1933, participando durante la Guerra Civil en varios frentes. Al terminar ésta marchó al exilio, primero en un campo de concentración
} 
aportaban, al haberse incorporado a $R E I$ con posterioridad. Años más tarde, en 2008, Luis Zaragoza publicaba su trabajo sobre $R E I$, abordando el conjunto de su historia.

El presente artículo forma parte de un proyecto de investigación en curso sobre el PCE y la guerrilla antifranquista, lo que explica el enfoque dado al mismo, centrado en los mensajes e información emitida por $R E I$ hacia la guerrilla y su influencia. Para ello he recurrido a la documentación depositada en el Archivo Histórico del PCE, destacando la serie de artículos para $R E I$ de Dolores Ibárruri, las memorias de Baudelio Sánchez ${ }^{3}$, los planes de trabajo en la emisora y los consejos para la lucha incluidos en la sección «Movimiento Guerrillero». Asimismo se analizan varias publicaciones de la época ligadas al PCE (España Popular, Reconquista de España y Mundo Obrero), o propias del movimiento guerrillero, como Ataque o El Guerrillero, entre otras. Finalmente destacar los datos sobre su «escucha» que ofrecen los trabajos de Ferrán Sánchez, Manuel Martorell, Luis Miguel Sánchez Tostado, Salvador F. Cava o Josep Cervelló ${ }^{4}$ sobre la guerrilla en España, así como las memorias de antiguos guerrilleros como Francisco Martínez «Quico» o Esperanza Martínez ${ }^{5}$.

\section{RADIO ESPAÑA INDEPENDIENTE, AÑOS 40}

A lo largo de su historia la radio ha jugado, en no pocas ocasiones, un relevante papel por su capacidad para transmitir las noticias o hechos en «tiempo real» y su difusión, superando barreras infranqueables para otros medios. El 22 de junio de 1941 fue una de ellas. Primero Hitler desde Radio Berlín y más tarde Molotov, desde Radio Moscú, anunciaban el paso de las fronteras soviéticas por los ejércitos alemanes.

argelino y posteriormente en la URSS, incorporándose a Radio Moscú en 1944. A finales de 1954 se trasladó a Bucarest para trabajar en la edición española de «Por una paz duradera, por una democracia popular», dependiente de la Kominform. Al disolverse ésta, el 17 de abril de 1956, pasó a REI como redactor. Fue también un excelente traductor de Fadeiev, Scholojov y Nekrasov. GALÁN, L: Después de todo: recuerdos de un periodista de la Pirenaica. Barcelona, Anthropos, 1988.

${ }^{3}$ Baudelio Sánchez «Jorge del Prado» se incorporó a REI durante su primera etapa en Moscú, permaneciendo en ella como redactor y locutor hasta su cierre en 1977. SÁNCHEZ, B: Cuarenta años después... recuerdos de un exiliado político español. Archivo Histórico del PCE (AHPCE), sección Tesis, Manuscritos y Memorias, sig. 74. Texto mecanografiado.

4 SÁNCHEZ AGUSTÍ, F: Maquis y Pirineos. La gran invasión (1944-1945). Lleida, Editorial Milenio, 2001; MARTORELL PÉREZ, M: Jesús Monzón, el líder comunista olvidado por la Historia. Pamplona, Pamiela, 2000; SÁNCHEZ TOSTADO, L. M: La Guerra no acabó en el 39. Lucha guerrillera y resistencia republicana en la provincia de Jaén (1939-1952). Jaén, Editora Distribuidora "El Olivo"-Patronato de Cultura y Turismo del Ayuntamiento de Jaén, 2001; FERNÁNDEZ CAVA, S: Los guerrilleros de Levante y Aragón. 1 la lucha armada (1945-1948). Cuenca, Tomebamba Ediciones, 2007, y SÁNCHEZ CERVELLÓ, J (Ed.): Maquis: el puño que golpeó al franquismo. La Agrupación Guerrillera de Levante y Aragón (AGLA). Barcelona, Flor del Viento Ediciones, 2003.

5 MARTÍNEZ, E: Guerrilleras, la ilusión de una esperanza. Madrid, Latorre Literaria S.A., 2010 
Al día siguiente tuvo lugar una importante reunión en la sede de la Internacional Comunista (IC) o Komintern convocada por su secretario general Georgi Dimitrov para analizar, entre otras cuestiones su papel en la nueva coyuntura. En la discusión, Dimitrov planteó «reconvertir» la IC en una emisora internacional de radiodifusión, idea que sería acogida con entusiasmo por todos los asistentes. El 6 de julio, la Unión Soviética daba luz verde a la propuesta de crear transmisiones radiofónicas no oficiales (clandestinas) en distintos idiomas. Serían emisiones impulsadas y coordinadas por la Komintern, si bien su paternidad no aparecería explícita, presentándose como propias de cada país 6 .

Trabajando contra reloj para preparar la infraestructura necesaria (salas de redacción, estudios, transmisores, etc.), el 22 de julio de 1941 salió al aire el programa dirigido a España. Había nacido Radio España Independiente, con Dolores Ibárruri al frente. Por las mismas fechas comenzaron a emitir Milano Aperta, Radio Finlandia Libre, o Radio Yogoslavia Libre, entre otras. Todas ellas compartían estudios, instalaciones técnicas y frecuencias, repartiéndose los horarios de emisión en turnos de treinta minutos. A medida que fueron liberándose los diferentes países se fueron suprimiendo los programas que se dirigían a ellos, aumentando el horario de emisión de los otros?

Los primeros pasos de REI fueron muy difíciles: dadas las condiciones que imponía la guerra, en ocasiones tenían que emitir desde un subterráneo. Por la noche, para evitar ser alcanzados por la aviación enemiga y por los constantes cortes de electricidad, trabajaban con luz de candiles y lámparas de aceite. Al carecer de información directa de España primero escuchaban otras emisoras como Radio Nacional de España, Radio París y Radio Londres, elaborando después la información con el material disponible. ${ }^{8}$ Baudelio Sánchez nos ha dejado su recuerdo sobre esta primera etapa en Moscú, desde su oficina en el Hotel Lux, sede de la Komintern:

«Siempre a la misma hora, el fantasioso, jactancioso y un poco anarquizante Echenique desaparecía del despacho llevando en el bolsillo un montón de folios mecanografiados (no por mí) y volvía desabrochándose el cuello de la camisa [...] Los que estaban en el ajo sabían el porqué de esto, pero nada decían. Secreto.» ${ }^{9}$

Ante el avance de las tropas alemanas, en el otoño de 1941 se decidió evacuar Moscú, trasladándose REI a Ufa, capital de la República de Bashkiria, cerca de los Urales. La sede de la Komintern, con la redacción de las diferentes emisoras, se instaló en el Palacio de los Pioneros, mientras que los programas se grababan y emitían desde el edificio de Correos.

6 ZARAGOZA FERNÁNDEZ, L: Radio Pirenaica. La voz de la esperanza antifranquista. Madrid, Marcial Pons Historia, 2008, pp. 26-27.

7 ZARAGOZA FERNÁNDEZ, L: Op. Cit. p. 28.

8 FALCÓN, I: Asalto a los cielos. Mi vida junto a Pasionaria, Madrid, Temas de hoy, 1996, p. 222.

9 SÁNCHEZ, B: Op. Cit. p. 123. 
En Ufa las fuentes de información seguían siendo casi nulas, viéndose obligados a trabajar con la escucha de las emisoras extranjeras, los documentos oficiales del PCE y las informaciones que suministraban los medios soviéticos, además de los textos que proporcionaba la Komintern.

En abril de 1943, REl regresaba a Moscú. Al mes siguiente, el 15 de mayo, la Komintern aprobaba su autodisolución, ${ }^{10} \mathrm{si}$ bien la mayor parte de su actividad continuó realizándose bajo otros nombres: el 12 de junio, en una reunión a la que asistió el propio Stalin, se aprobó la creación de un Departamento de Información Internacional, dentro del Comité Central del PCUS, encargado de dirigir los comités antifascistas, las emisiones radiofónicas nacionales clandestinas, el trabajo de otros países, la agencia telegráfica y la editorial de lenguas extranjeras. A partir de entonces las radios clandestinas trabajarían bajo la cobertura del denominado Instituto Científico 205, dedicado oficialmente a la investigación radiofónica.

«Dos veces al día - la primera a las seis y media de la tarde y la segunda hacia la media noche, hora moscovita-, bien Echenique o yo, por turno, descendíamos — que no subíamos - al Pirineos (sic) con nuestro tocadiscos bajo el brazo, más las cuartillas correspondientes. Entrábamos en el estudio, colocábamos en una silla nuestra música y después de tocar el Himno de Riego empezábamos la lectura.» ${ }^{11}$.

Buena parte de las emisiones en esta segunda etapa en Moscú se basaban en la reproducción de artículos procedentes de la prensa del PCE y del PSUC, como Mundo Obrero, España Popular, Treball y Nuestra Bandera. Se recibían también, aunque con más retraso, las publicaciones clandestinas editadas en España, con preponderancia de la prensa guerrillera. El único periódico español que se recibía con regularidad era $A B C$, llegando el resto de la prensa española con gran retraso. ${ }^{12}$

¿Cuál fue el papel que desempeñó REI en este periodo? Fundamentalmente el fijado por la Komintern para su creación: coordinar la acción de los comunistas españoles en defensa de la URSS, informándoles de las decisiones adoptadas por los miembros del Buró Político y del Comité Central.

Desde el final de la Guerra Civil el PCE se encontraba disperso por varios países y continentes: la Unión Soviética, América, Francia y España. Dadas las circunstancias, el único medio para que desarrollaran una política uniforme, al menos en sus líneas generales, era $R E I$, papel que seguirá jugando tras el trasla-

10 Como señala Juan Avilés, la función inicial de la Internacional, «la de promover la revolución en todos los países, no encajaba ya en la política de Stalin, centrada en la lucha de poder entre las grandes potencias, y tampoco era necesaria para asegurar la fidelidad a Moscú de los partidos nacionales". AVILÉS FARRÉ, J: La mujer y el mito. Pasionaria. Barcelona, Plaza y Janés, 2005, p. 158; PRESIDIUM DEL COMITÉ EJECUTIVO DE LA INTERNACIONAL COMUNISTA: «Resolución». Nuestra Bandera, México, 6, 1943, pp. 10-12.

11 SÁNCHEZ, B: Op. Cit. p. 143.

12 ZARAGOZA FERNÁNDEZ, L: Op. Cit. pp. 78-79. 
do de la dirección del PCE a Francia en 1945: «Constatamos con satisfacción que la falta de contacto no ha impedido que por vuestra propia cuenta, con la ayuda de $R E I$ y de los pocos materiales que han llegado a vuestras manos, hayáis orientado justamente al Partido, imprimiéndole además un alto espíritu combativo». ${ }^{13}$

Las campañas que se realizaban insistían en la ruina que significaba para España el falangismo en el poder, reiteraban que había que evitar por todos los medios que España entrara en la guerra al lado de Alemania, explicaban la barbarie hitleriana y los medios de sabotaje que se podían utilizar para combatir a los nazis o exaltaban la vida en la Unión Soviética y la lucha heroica de sus gentes. Desde septiembre de 1942, la Pirenaica realizó una constante campaña de popularización de la nueva estrategia adoptada por el PCE: la Unión Nacional. ${ }^{14}$

Con el tiempo, esta labor de dirección se verá reforzada, estableciéndose mecanismos (a través de mensajes cifrados) para orientar el trabajo del partido a través de $R E I$, en especial cuando los canales regulares establecidos no podían mantenerse como consecuencia de la acción represiva: «Es muy posible que en ciertas ocasiones, o incluso utilizando el código que os enviamos, os trasmitamos indicaciones y directivas políticas por esta radio. Esto con mayor motivo, si por cualquier circunstancia quedáramos cortados en un momento dado» ${ }^{15}$.

Debido a ello, la audición de REl y la transcripción de sus emisiones se convirtieron en una de las tareas más importantes para los dirigentes del PCE en esta época. A fin de facilitar esta labor, REI dedicaba sus últimas emisiones a transmitir en lectura lenta los textos más importantes del día. Fue el caso de Carmen de Pedro, en Francia, encargada por Jesús Monzón de transcribir las declaraciones, comentarios, textos o consignas difundidas por $R E I^{16}$ y de Carmen Casas "Elisa», encargada en Zaragoza de redactar los boletines tras escuchar la $B B C$ y $R E I^{17}$.

Como resultado de esta labor de escucha, no tardaron mucho publicaciones como Reconquista de España en incluir en sus páginas artículos o informes extraídos de $R E I$, anunciando a su vez el horario y longitud de onda de sus emisiones: «Tras varios ensayos para perfeccionarse técnicamente y mejorar sus condiciones de clandestinidad, la Estación Pirenaica Radio España Independiente ha normalizado sus programas» ${ }^{18}$.

El 16 de septiembre de 1942 se hacía público a través de REI el que ha sido considerado como el documento fundacional de Unión Nacional, firmado por el Comité Central del PCE. El 25 de septiembre aparecía en las páginas de España

${ }^{13}$ AHPCE, sección Varios. Años 40, jacques 25-30. BURÓ POLÍTICO DEL PCE: «Carta a Galicia».

14 ZARAGOZA FERNÁNDEZ, L: Op. Cit. pp. 51-52.

15 Trascrito del original, descifrando las claves. AHPCE, sección Varios. Años 40, jacques 25-30. BURÓ POLÍTICO DEL PCE: «Carta a Galicia».

16 En septiembre de 1941 tal tarea fue posible al conseguir un receptor de radio en Aix-en-Provence (Francia), donde residían Carmen de Pedro y Jesús Monzón. MARTORELL PÉREZ, M: Op. Cit. pp. 98-99.

17 SÁNCHEZ AGUSTÍ, F: Op. Cit., p. 200.

18 «Atención, españoles». Reconquista de España, Francia, 6, 1941, p. 4. 
Popular, ${ }^{19}$ y también se reprodujo en el número de septiembre de la revista teórica del PCE Nuestra Bandera ${ }^{20}$.

\section{REI Y EL MOVIMIENTO GUERRILLERO ESPAÑOL}

Durante la década de los años 40, la táctica del PCE estuvo ligada al desarrollo y fortalecimiento del movimiento guerrillero, en el marco de una estrategia política de «unidad nacional» orientada a la «reconquista» de las libertades y la República en España mediante la insurrección nacional. Un proceso similar al que se daba en todo el continente en aquellos países invadidos por los nazis: Francia, Yugoslavia, Grecia, etc.

El primer problema con que nos encontramos a la hora de analizar el apoyo brindado por REI a los guerrilleros españoles es la falta de información sobre sus emisiones. De esta época, según señala Irene Falcón, «no se han conservado ni los artículos ni las cintas porque una inundación, años más tarde, destruyó los archivos de Radio España Independiente durante su etapa en la URSS» 21 . Con todo, en los archivos del PCE se conservan diversos artículos de Dolores Ibárruri y algunos documentos sobre planes de trabajo, comentarios, etc. ${ }^{22} \mathrm{~A}$ ello se suman las transcripciones y referencias a sus emisiones que podemos encontrar en las publicaciones de la época. Veamos en primer lugar los documentos conservados:

a) «Organización del trabajo en la redacción española». Fechado el 15 de noviembre de 1942. En él aparecen las tareas asignadas a cada uno de los miembros de la redacción, encargándose a Enrique Castro: la sección diaria «Instrucciones para el sabotaje», la emisión de los miércoles «de guerrilleros» y las campañas «sobre el sabotaje» y «por el desarrollo y ampliación del movimiento guerrillero» ${ }^{23}$.

\footnotetext{
19 «Un vibrante llamamiento del C.C. del Partido Comunista de España». España Popular, México, 101, 1942, p. 1.

20 «Llamamiento del Comité Central del Partido Comunista de España». Nuestra Bandera, México, nำ5, 1942, pp. 1-5.

21 FALCÓN, l: Op. Cit. pp. 225-226.

22 Según Baudelio Sánchez, «porque en nuestra emulación socialista incluíamos un punto consistente en recopilar en carpetas aparte las colaboraciones de los máximos dirigentes de la Pirenaica». SÁNCHEZ, B. Op. Cit. p. 145.

${ }^{23}$ El resto de tareas asignadas fueron:

- A Dolores Ibárruri: los editoriales de los lunes y miércoles; un artículo para las emisiones dedicadas a los obreros, a las mujeres y a la juventud; la charla semanal del «Diablo Cojuelo», y la «Emisión para mujeres».

- A Francisco Antón: Ios editoriales de los martes, viernes y sábados; las secciones diarias «Noticias de la guerra» y «Unidad nacional y organización»; un artículo a la semana sobre la demagogia falangista; las emisiones «para obreros» y «para el Ejército» y las campañas «La Unidad Nacional y las formas de organización de esta unidad» $y$ «por la neutralidad»
} 
b) «Proyecto de Plan para los próximos 15 días». En éste, se proponen para las emisiones de los días 8 y 15 de septiembre de 1943 los siguientes artículos: «El honor de ser guerrillero» y «Los guerrilleros los mejores difusores de la propaganda juvenil» ${ }^{24}$.

c) «Sobre el trabajo a realizar». Tras un análisis de la situación política en España, se señalan los siguientes artículos para la emisión del miércoles, dedicada al movimiento guerrillero: «1. Cómo unificar y ampliar el movimiento de guerrilleros y desarrollar sus luchas. 2. Los objetivos actuales de los guerrilleros en el campo y la ciudad» ${ }^{25}$. Y para la emisión de la noche: «1. Franco el representante supremo de la política exterior hitleriana y de la política interior de hambre y terror. 2. Lo que hay que exigir e imponer con la lucha (la amnistía total, el derecho de asociación y anulación de la legislación fascista de Falange). 3. Editorial» 26 .

d) «Movimiento guerrillero» 27. En esta sección del Archivo Histórico del PCE se conservan un conjunto de artículos emitidos por REI entre 1942 y 1948 sobre la lucha guerrillera y consejos sobre la realización de sabotajes o la edición de propaganda. Básicamente se pueden englobar en:

- Instrucciones para el desarrollo de la lucha guerrillera, con indicaciones sobre métodos de resistencia pasiva, sabotaje y diversión: descarrilamiento y destrucción de trenes y vehículos automóviles, sabotaje de fábricas de

- A Enrique Castro: los editoriales del domingo y del lunes, la sección semanal «Palabras y hechos de Falange» y la sección diaria «Comentario internacional», así como la campaña «por la organización de luchas obreras".

- A Julio Mateu: las secciones trisemanales «Nada para Alemania» y «La vida en provincias»; la «Emisión campesinos» y las campañas «Nada para Alemania» y «por el desarrollo y organización de la lucha en el campo».

- A Irene Falcón: la sección trisemanal «Contra el hambre y la vida cara», un artículo semanal sobre «El verdadero 'nuevo orden' en Europa», y tres artículos para la emisión semanal dedicada a la mujer, así como las campañas «contra el hambre y la vida cara», «contra la organización de las mujeres» y «contra la barbarie hitleriana».

- A Ramón Barros «Moncho»: un artículo diario para la sección «Rincón de la Juventud»; la «Emisión juvenil», y las campañas por la organización del «Frente Nacional de la Juventud» y «por la deserción, el sabotaje y la lucha en el Ejército».

- A Vicente Pertegaz: dos artículos semanales sobre «Lo que la URSS está haciendo por la victoria» y un artículo semanal «Reivindicaciones populares», así como la campaña «por la exaltación de la vida soviética».

- A José María Echenique: la crónica semanal «La vida de América Latina» y un artículo a la semana sobre Euskadi o Cataluña.

- A Enriqueta Lewy «Kety», hermana de Irene Falcón: la sección diaria Noticiario internacional.

AHPCE, sección $R E l$, caja 165, carpeta 7. «Organización del trabajo en la redacción española». 15 de noviembre de 1942.

24 AHPCE, sección REl, caja 165, carpeta 17. «Proyecto de Plan para los próximos 15 días». 3 de septiembre de 1943.

${ }_{25}$ AHPCE, sección REI, caja 165, carpeta 8. IBÁRRURI, D: «Sobre el trabajo a realizar».

26 Ibidem.

27 AHPCE, sección Movimiento Guerrillero, caja 105, carpeta 1, documento 1. «Instrucciones para el desarrollo de la lucha guerrillera. Transmitidas por Radio España Independiente». 1942-1948. 
guerra, voladura de los postes de alta tensión, organización de golpes de mano, colocación de minas y fabricación de botellas inflamables y petardos y explosivos (con pólvora o amonal, entre otros).

- Instrucciones y consejos sobre la reproducción y reparto de propaganda: tanto para la preparación de tintas y aparatos reproductores (con gelatina, caolín, arcilla o placas fotográficas), como para la distribución de la propaganda (en fábricas, paradas del tranvía, escaleras de vecindad, y otros lugares). Consejos a los radioescuchas.

- «Dirigentes». En esta sección del Archivo Histórico del PCE se guardan una serie de colaboraciones de Dolores Ibárruri para $R E I$, con llamamientos a la lucha contra Hitler y Falange y de apoyo al movimiento guerrillero:

- «Los momentos de las acciones decisivas». En defensa del pueblo soviético: «Porque ayudarle a él, es ayudarnos a nosotros mismos» 28 .

— « ¿Adónde llevan a tu hijo, mujer?». Dirigido a las madres de los soldados movilizados: «No consientas que tu hijo se presente en el cuartel o en el Ayuntamiento. Aconséjale que se eche al monte» 29 .

- «Política de guerra de Falange». En él hace un llamamiento a los jóvenes mineros para que impidan que Falange realice sus planes de guerra ${ }^{30}$.

- «El papel de los guerrilleros en la lucha por la independencia de los pueblos». Sobre la tradición guerrillera en España y la extensión de la lucha en Europa $^{31}$.

- «Ayudemos a los guerrilleros y reforcemos la lucha en nuestro país». Llamamiento a la población para que apoye a los guerrilleros, los cuales «se juegan la libertad y la vida cada día, manteniendo en alto la bandera de la República en las cimas y en los canchales de nuestros montes» 32.

${ }^{28}$ AHPCE, sección Dirigentes, caja 14, carpeta 2, documento 1. IBÁRRURI, D: «Colaboraciones para $R E \mid \gg .5$ de octubre de 1942.

29 AHPCE, sección Dirigentes, caja 14, carpeta 2, documento 2. IBÁRRURI, D: «Colaboraciones para $R E l » .29$ de noviembre de 1942.

30 «Producid poco, estropead las bombas de desagüe, minad los machones; cortad la corriente eléctrica; estropead los motores; dejad que se estropeen las bocas de los barrenos; cargad mal los tiros; agujeread los tubos de las perforadoras». AHPCE, sección Dirigentes, caja 14, carpeta 2, documento 4. IBÁRRURI, D: «Colaboraciones para REI». 4 de diciembre de 1942.

${ }^{31}$ «Los hombres que después de haber luchado durante tres años por la libertad de España se han refugiado en nuestras montañas, manteniendo vivo el espíritu de revuelta y de insurrección contra los que han esclavizado y ensangrentado España, son nuestro orgullo y nuestra gloria». AHPCE, sección Dirigentes, caja 14, carpeta 3, documento 2. IBÁRRURI, D: «Colaboraciones para REl». 3 de marzo de 1943.

32 AHPCE, sección Dirigentes, caja 14, carpeta 3, documento 3. IBÁRRURI, D: «Colaboraciones para $R E / \gg .7$ de abril de 1943. 
- «Por la vida de los nuestros». Con una clara advertencia a Falange: «Por cada uno de nuestros hombres ejecutados [...] deben caer tres cabezas falangistas. De grandes caciques o de pequeños caciques» ${ }^{33}$.

Hemos visto cómo REI prestó una atención destacada al movimiento guerrillero (emisiones de los miércoles, colaboraciones de Dolores Ibárruri, consejos y orientaciones para la lucha, etc.), sin embargo, ¿se escuchaba en España? Según señala Dolores lbárruri en sus Memorias, la redacción española fue la primera en tener constancia de que, en efecto, su voz se recibía en el país: «Llegaron a nosotros periódicos manuscritos por los guerrilleros de diversas regiones de España, en las que se reproducían textualmente trabajos de nuestras emisiones. Se nos oía y se repartían nuestros artículos entre camaradas y amigos» ${ }^{34}$.

De la misma opinión es España Popular, publicación del PCE editada en México, la cual incluye a partir de 1942 diversas noticias sobre REI, con declaraciones de españoles indicando que la emisora se escuchaba en el interior del país: «Acaba de llegar de España un antiguo empleado de Juan March, quien relata las actividades estraperlistas de dicho señor [...]. Este mismo individuo dice que se escucha Radio España Independiente, aunque con perturbaciones en la parte Sur de nuestro país» 35 .

En 1943 España Popular publica varias noticias que «muestran el interés con que los patriotas españoles escuchan las emisiones de $R E \mid{ }^{36}{ }^{36}$. Como ejemplo de ellas, se reproduce una sobre Cataluña:

«Todos los días millares de catalanes escuchan la Radio España Independiente que funciona en los Pirineos. Grupos de antifranquistas se reúnen en casas de gentes de confianza para oír la emisión, y la información que la misma facilita circula después, bien escrita a máquina o por otros medios, entre los trabajadores y el pueblo ${ }^{37}$.

Otra prueba de su audiencia en el interior de España serían las menciones a $R E I$ en la prensa y radios oficiales, particularmente en Radio Nacional de España. Las primeras noticias directas se tienen en noviembre de 1944, dado que con anterioridad «nuestro servicio de escucha de la radio franquista era débil» ${ }^{38}$.Por estas

\footnotetext{
${ }^{33}$ AHPCE, sección Dirigentes, caja 14, carpeta 3, documento 3. IBÁRRURI, D: «Colaboraciones para REl». 14 de abril de 1943. Declaraciones similares aparecen también en publicaciones guerrilleras, como Ataque: "Que cada asesino falangista sienta sobre su cabeza la espada de Damocles de la justicia guerrillera. Respondamos a los cientos y cientos de ejecuciones diarias, a las bárbaras torturas de las cárceles, con la acción justiciera de los guerrilleros. Por cada antifranquista asesinado deben morir diez falangistas». Ataque, 6, agosto de 1945.

34 IBÁRRURI, D: Memorias de Pasionaria, 1939-1977. Barcelona, Editorial Planeta, 1984, p. 54.

35 «Noticias de Londres». España Popular, 83, México, 17 de enero de 1942, p. 1

${ }^{36}$ AHPCE, sección REI, caja 165, carpeta 6. «Algunos ecos y comentarios a Radio España Independiente». 13 de julio de 1949.

37 «Escuchan Radio España Independiente». España Popular 141, México, 18 de junio de 1943, p. 2.

${ }^{38}$ AHPCE, sección REI, caja 165, carpeta 6. «Algunos ecos y comentarios a Radio España Independiente». 13 de julio de 1949.
} 
fechas, $R N E$ reproduce a veces párrafos de $R E I$, diciendo «esa llamada Radio España Independiente», «una amable radio extranjera», o simplemente contestando a lo que REI dice. ${ }^{39}$ Con el tiempo, los ataques a la emisora se hacen más frecuentes y virulentos, manifestando la preocupación creciente del franquismo por las emisiones de Radio España Independiente: «El bajo estilo de los ataques de una emisora extranjera, cuya ubicación geográfica es obvio mencionar, dirigidos contra el general Franco, se compagina con el nivel infra-animal de los locutores.... ${ }^{40}$.

Hay también documentados varios casos de personas detenidas en España por reunirse con otros vecinos a escuchar REl. Entre ellos cabe citar el caso de Agustín Carretero Raga, secretario provincial de Izquierda Republicana, en cuya casa de Sotos (Cuenca) se reunía con varios vecinos de la localidad para escuchar la radio (Radio Andorra, La Pirenaica, la BBC, Radio París) y comentar las novedades de los frentes. Fueron detenidos en agosto de $1943^{41}$. Lo mismo les sucedería a los hermanos Francisco y Sebastián Jiménez, de Navas de San Juan (Jaén), detenidos en enero de 1947 junto a más de 30 vecinos $^{42}$, y a los hermanos Eufemio y Daniel Bolós Silvestre, cuya familia regentaba un bar en Valbona (Teruel): denunciados por un vecino, tuvieron que huir al monte en marzo de 1947, incorporándose al $17^{\circ}$ Sector de la Agrupación Guerrillera de Levante y Aragón ${ }^{43}$. $O$, finalmente, el caso de Alfonso Martínez Pena, en cuya casa solía reunirse con Antonio Mercader y Sergio Moya para escuchar REI. Fueron detenidos y sometidos a consejo de guerra en Cartagena el 9 de diciembre de $1944^{44}$.

En tal sentido, resulta ilustrativo el caso de Josep Borrás Climent «Cinctorrá» quien, tras retornar de Francia en 1943 y permanecer un tiempo escondido en su casa, formó grupo con José Linares Beltrán «Valencia», Josep Sangüesa «Elietes» y Francisco Salvador Sebastiá «Conill d'Ares» y «juntos escuchaban La Pirenaica, las emisiones de la cual incitaban a la creación de unidades guerrilleras para combatir el franquismo. Fue este martilleo propagandístico lo que impelió al grupo a la resistencia armada» 45 .

39 Ibidem.

40 Ibidem.

41 FERNÁNDEZ CAVA, S: Op. Cit., pp. 54-56.

42 SÁNCHEZ TOSTADO, L. M: Op. Cit., p. 290.

43 SÁNCHEZ CERVELLÓ, J (Ed.): Op. Cit., p. 343.

44 Según el Tribunal: «Resultando: que durante un periodo de tiempo que no se ha podido precisar, pero de bastante duración, se venían celebrando, en el domicilio del procesado Alfonso Martínez Peña (...) reuniones frecuentes so pretexto de oír la radio, pero en realidad para aprovechar la escucha de emisoras rusas y clandestinas de Toulouse y Pirenaica con objeto de, a través de encendidos comentarios y exposición de doctrinas a que daban lugar las propagandas de dichas emisoras, apoyar, favorecer y hacer eficaz la agitación de tipo subversivo y la más mediata pero directa preparación de una rebelión en nuestra Patria, que sería reanudación de la feroz revolución marxista-separatista vencida por la Gloriosa Cruzada de Liberación, con todas las criminales características de aquélla». Considerando que tales hechos tenían «todas las características de un delito de rebelión militar», fueron condenados a muerte los operarios Alfonso Martínez Peña, Antonio Mercader Cañabate y Sergio Moya Sevilla. Martínez Peña fue fusilado y los otros dos vieron conmutada su pena por la inmediatamente inferior en grado. ZARAGOZA FERNÁNDEZ, L: Op. Cit. p. 393.

45 SÁNCHEZ CERVELLÓ, J : Op. Cit. pp. 82-83. 
A partir de 1944 comenzaron a llegar a Moscú publicaciones guerrilleras en las que se recogían los «partes de operaciones» de las distintas unidades. Así, aunque fuera con retraso, REI pudo redifundir esas informaciones y mostrar a cada agrupación que no estaba sola en la lucha. ${ }^{46}$

A título de ejemplo, se puede citar una de las noticias aparecidas en Ataque, boletín del Alto Mando Guerrillero de la Junta Suprema de UN, en abril de 1945: «Zona Centro-Extremadura: Unidades de esta Agrupación sostuvieron combate con la Guardia Civil en los últimos días de Marzo, en las inmediaciones de Navahermosa, causando 5 muertos al enemigo. Por nuestra parte sufrimos dos muertos». ${ }^{47}$

Lo mismo sucede con el resto de publicaciones guerrilleras consultadas: El Guerrillero, órgano de la Agrupación Guerrillera de Levante, Boletín de Información, de la Federación del Norte de España, El Guerrillero, órgano del Ejército Guerrillero de Galicia, El Guerrillero Carpetano, órgano de la Agrupación Zona M, Guerrillero Extremeño, órgano de la Agrupación Guerrillera de Extremadura, Por la República, editado por la Agrupación Guerrillera de Málaga, etc. Asimismo se hacían eco de las noticias y consejos de lucha emitidos por REl:

- «ÚLTIMA HORA. La emisora de la Resistencia nos comunica que una patrulla guerrillera ha ajusticiado al juez franquista de Domeño (Valencia), a el "Lobico», delator de guerrilleros y culpable de la muerte de uno de nuestros camaradas en las cercanías de la masía Jórgola, término de Calles. ${ }^{48}$

- «CÓMO CONFECCIONAR UNA MINA. Llenar una botella con 500 gramos aproximadamente de una mezcla preparada ya... ${ }^{49}$

Según las declaraciones del guerrillero leonés Francisco Martínez "Quico», recogidas por Luis Zaragoza:

«Éramos una guerrilla urbana y parábamos en las casas, y allí escuchábamos La Pirenaica. Pero aparte teníamos los puntos de apoyo, donde teníamos a gente encargada de escucharla cuando nosotros no podíamos y darnos la información. $Y$ algunas acciones de las nuestras buscábamos los medios para que llegasen a Radio Pirenaica.» ${ }^{50}$

Que REI era escuchada «por los del monte», lo atestigua asimismo Esperanza Martínez, guerrillera de la AGLA, en sus memorias:

«Escuchábamos la radio si por causa de las interferencias era posible, pero era difícil, sobre todo si se trataba de Radio España Independiente, LA PIRENAICA».51

\footnotetext{
46 ZARAGOZA FERNÁNDEZ, L: Op. Cit. pp. 105-106.

47 «Parte de operaciones del Alto Mando Guerrillero». Ataque, 1, abril de 1945, p. 2.

48 «Última hora». El Guerrillero, Agrupación Guerrillera de Levante, agosto de 1949.

49 «Cómo confeccionar una mina». El Guerrillero, 2, Ejército Guerrillero de Galicia, 31 de enero de 1947, p. 3.

50 ZARAGOZA FERNÁNDEZ, L: Op. Cit. p. 10.

51 MARTÍNEZ, E: Op. Cit. p. 45.
} 
Junto a los partes de operaciones y comunicados políticos o de orientación dirigidos a la población, otra de las funciones de REI fue la emisión de mensajes cifrados, informando sobre la actividad de las fuerzas represivas. Uno de ellos fue transmitido en el verano de 1948, abortando el operativo montado por la Guardia Civil para aislar y aniquilar a los hombres de Manuel Pablo Pérez Cubero «Rubio», pertenecientes al 17ํ Sector de la Agrupación Guerrillera de Levante y Aragón ${ }^{52}$. ¿Cómo había llegado la noticia a la radio? Todo parece indicar que fue a través del servicio de radio-escucha instalado por el PCE en París ${ }^{53}$.

Para perturbar las emisiones de REI se creó en España una Junta Interministerial de Interferencias radiadas que afectaban, según señala Fernández de Baños, a las «emisoras comunistas y bolcheviques de los enemigos de España». ${ }^{54}$

También estaba el control que ejercían las fuerzas represivas sobre las escuchas de las emisiones ilegales o extranjeras. Para saltarse tales controles, y evitar ser descubiertos, el 21 de abril de 1944 REI emitía "Consejo a los radioescuchas», 55 con indicaciones sobre cómo actuar en caso de confiscación de aparatos o para la creación de grupos de radio-escuchas.

En 1948, tras una reunión celebrada en Moscú con Stalin, a la que asistieron Dolores Ibárruri, Francisco Antón y Santiago Carrillo, el PCE adopta un cambio de táctica, abogando por el trabajo político en el seno de las organizaciones legales de masas. Lo que no supuso «desmantelar» las guerrillas, sino la asunción por éstas de nuevas tareas:

«El objetivo [de los guerrilleros] debe ser crear "Consejos de la Resistencia" en cada pueblo, organizar, por todos los medios posibles, a los obreros agrícolas, a los campesinos pobres y medios, y ayudarles a utilizar todos los medios de lucha, aconsejándoles a aprovechar, con habilidad y audacia, las mismas "Hermandades", "Sindicatos", "Cooperativas"..." ${ }^{56}$.

\footnotetext{
52 Incorporado en 1947, dos años antes había creado una red en el Gobierno Militar de Teruel consiguiendo las claves cifradas que usaba la Guardia Civil y otras informaciones de interés militar. SANCHEZ CERVELLÓ, J (Ed.): Op. Cit. pp. 290-291 y 473.

53 Según señala Santiago Carrillo en sus Memorias: «Poseíamos también un centro de escucha de radio, servido por camaradas radistas y expertos en descodificar que había trabajado en la flota de guerra republicana. Éstos mantenían nuestra relación por radio con agrupaciones guerrilleras y organizaciones del partido y además captaban todos los mensajes de la Guardia Civil y de la policía; tales mensajes al principio eran emitidos de manera abierta, hasta que las autoridades franquistas se dieron cuenta de nuestra interceptación y empezaron a utilizar códigos. Pero los descodificadores consiguieron descubrirlos todos y gracias a ello, por ejemplo, pudimos desmontar una gran ofensiva de Ejército y Guardia Civil en la zona de Levante advirtiendo de ella a través de Radio España Independiente». CARRILLO, Santiago: Memorias. 3aㅡ Edición. Barcelona, Planeta, 2007, pág. 432.

54 MARTÍNEZ DE BAÑOS, F: El Maquis. Una cultura del exilio español. Zaragoza, Editorial Delsan, 2007, p. 242.

55 AHPCE, sección Movimiento Guerrillero, caja 105, carpeta 1. «Consejo a los radioescuchas», 21 de abril de 1944.

56 AHPCE, sección Movimiento Guerrillero, caja 105, carpeta 1, documento 1. «Las tareas fundamentales de los guerrilleros en esta etapa de la lucha». 12 de octubre de 1949.
} 
Sin embargo tal situación no resultaba sostenible a medio plazo para las guerrillas que aún operaban en España (Galicia, Granada y Levante-Aragón, fundamentalmente). Los cambios habidos en la sociedad española, puestos de manifiesto con la huelga de tranvías de Barcelona (1951), junto a la situación internacional de "guerra fría» y la persecución a la que se veían sometidos los comunistas españoles en Francia tras la operación «Bolero-Paprika» (1950), llevó al PCE a ordenar su desmovilización.

Se iniciaba con ello una nueva etapa para REI, con el nombramiento de Ramón Mendezona como director a finales de 1951 y su traslado a Bucarest en enero de 1955, permaneciendo en esta ciudad hasta su clausura en 1977.

\section{CONCLUSIONES}

Creada para coordinar la acción de los comunistas españoles, dadas las dificultades existentes para llevar a cabo esta tarea de otro modo, REI jugará un papel destacado a lo largo de los años 40 , tanto en lo que se refiere a la organización del PCE, como al movimiento guerrillero español en su conjunto y más particularmente al de disciplina comunista.

Las referencias a las labores de escucha son numerosas, según hemos puesto de manifiesto, tanto en las memorias de antiguos guerrilleros consultadas como en las publicaciones "del interior», de las que REI se hará eco, poniendo de manifiesto la «amplitud» y «extensión» de la resistencia al régimen franquista. Las publicaciones servirán a su vez de altavoz, reproduciendo las noticias y comunicados radiofónicos, amplificando la penetración de REI y del PCE entre la población española.

Asimismo, por la documentación conservada en el Archivo Histórico del PCE cabe asegurar, pese a su carácter fragmentario, la voluntad de intervenir por parte de la dirección del PCE, a través de REI, en la evolución y desarrollo del movimiento guerrillero español, combinando las labores de formación (en el manejo de explosivos o la producción de propaganda) con las más directamente políticas, dirigidas a promover la insurrección nacional o la participación de las organizaciones guerrilleras en la acción opositora con la creación de los Consejos de la Resistencia.

A finales de los años 40 tal estrategia «insurreccional» se juzgará fallida, iniciando el PCE el camino que le llevará en los años 50 a propugnar la «reconciliación nacional» para acabar con el franquismo. Para esta nueva etapa REI cambiará su equipo directivo, con Ramón Mendezona al frente, y se trasladará a Bucarest, donde permanecerá hasta su cierre en 1977. 
